\title{
EUROPEAN POPULISM IN THE SHADOW OF THE GREAT RECESSION \\ [Hanspeter Kriesi e Takis S. Pappas, 2015, Colchester, ECPR Press]
}

\author{
Vicente Valentim \\ Instituto Universitário de Lisboa (ISCTE-IUL), Lisboa, Portugal
}

European Populism in the Shadow of the Great Recession tem como objetivo analisar a forma como a recente crise económica e financeira potenciou o aumento do populismo na Europa.

Os autores começam por reconhecer que o crescimento do populismo não é consequência apenas da crise, constituindo antes um processo de longo prazo, fruto do mau funcionamento da democracia representativa de um modo geral e, mais concretamente, dos sistemas partidários europeus, que deveriam desempenhar o papel de ligação entre cidadãos e processos de tomada de decisões políticas. Estes problemas, por sua vez, têm origens diferentes, consoante a região europeia que se considere. Na Europa Ocidental são consequência de uma redução da capacidade de mobilização dos partidos políticos mainstream, enquanto na Europa Central e de Leste resultam de os sistemas partidários dessa região nunca se terem chegado a institucionalizar, o que, aliado aos fortes sentimentos antielites que aí se fazem sentir, facilitou o aparecimento do populismo.

Os autores chamam também a atenção para a necessidade de distinguir entre crise económica e crise política. Apesar de haver uma forte relação entre ambas e de muitos países terem sofrido tanto uma como outra, estas constituem fenómenos distintos a nível teórico e empírico, não devendo assim ser confundidos.

Posto isto, a questão a que a obra procura responder é a de até que ponto estes dois tipos de crise agudizaram a tendência de longo prazo no sentido de um crescimento do populismo no espaço europeu. Desta forma, os autores começam por definir o seu objeto de estudo. Ainda que reconheçam que o populismo pode existir tanto enquanto ideologia como enquanto estratégia política, o seu interesse recai sobre a primeira. Assim, baseando-se no trabalho de Mudde (2004), identificam quatro características centrais do populismo enquanto ideologia: a crença na existência de dois grupos homogéneos - o "povo" e a "elite"; a relação antagónica entre eles; o foco na ideia de soberania popular; e uma lógica maniqueísta que valoriza positivamente o povo, ao mesmo tempo que deprecia a elite. No entanto, este núcleo central do populismo é algo "fino", no sentido de ser incapaz de dar resposta a um conjunto alargado de questões políticas, o que faz com que muitas vezes seja combinado com ideologias mais "espessas", como sejam o conservadorismo, à direita, ou o socialismo, à esquerda. Os autores referem-se também ao facto de o populismo ter uma visão bastante antiliberal da democracia, pese embora o seu foco na soberania popular. Tal acontece por três motivos: por o seu foco no governo popular, entendido de forma literal, levar a uma negação dos checks and balances que são centrais na conceção de democracia liberal; pela sua hostilidade a 
intermediários entre o povo e os decisores políticos, principalmente aos partidos políticos; e pela sua visão monolítica do povo, não deixando espaço ao pluralismo que é também uma característica central da democracia liberal. No entanto, ainda que sendo hostil aos partidos, o populismo tem neles o seu principal veículo organizacional, tendendo os líderes populistas a criar um partido ou a apropriar-se de um já existente, como forma de chegar ao poder. Tanto assim é que o livro se centra essencialmente na análise de partidos populistas.

Definido o objeto de estudo central do livro, os autores avançam um conjunto de hipóteses relativamente à sua relação com a crise. A primeira é a de que o populismo terá crescido em países mais afetados pela crise económica, dada a capacidade que esta tem de aumentar o antagonismo entre povo e elite, do qual o populismo se alimenta. Seguidamente, os autores avançam a hipótese de o populismo ter também aumentado em países onde houve crise política, já que esta cria sentimentos antielitistas que também o favorecem. Por sua vez, o efeito conjunto destas duas crises deverá ter sido particularmente benéfico para o crescimento do populismo, $\mathrm{o}$ que corresponde à terceira hipótese da obra. Por último, esta procura também analisar o efeito da experiência governativa sobre partidos populistas, esperando-se que conduza a uma moderação do seu discurso, levando estes partidos a comportarem-se de forma mais semelhante à dos partidos políticos mainstream.

No que diz respeito à operacionalização das variáveis independentes, os autores debruçam-se sobre um conjunto de indicadores económicos (taxa de crescimento, taxa de desemprego e dívida pública) para verificar a existência ou não de crise económica; e para indicadores atitudinais (confiança nas instituições e satisfação com a democracia) e comportamentais (volatilidade eleitoral) para verificar a existência ou não de crise política. Já a variável dependente é medida pelos ganhos - ou perdas - eleitorais dos partidos populistas.

Posto isto, o livro organiza-se em 18 capítulos, que incluem a introdução, a conclusão e um capítulo dedicado a cada um dos 17 casos nacionais estudados (sendo um dos capítulos dedicado a dois países em simultâneo: Noruega e Dinamarca). Estes 18 capítulos distribuem-se por cinco partes, cada uma correspondendo a uma das regiões europeias estudadas: a Nórdica; a Ocidental; a do Sul; a do Centro e Leste; e a Anglo-Céltica.

Relativamente à primeira, de um modo geral pouco afetada pela crise económica e onde tão-pouco se puderam verificar reais crises políticas, os autores concluem que o populismo, como esperado, sofreu perdas eleitorais na Dinamarca e Noruega, mas cresceu na Finlândia e na Suécia. No entanto, o primeiro destes casos explica-se pelo facto de a crise económica usada na retórica populista como forma de mobilização ter sido a crise da zona euro, e não a crise doméstica. Já o sucesso do populismo na Suécia pode explicar-se por uma tendência de longo prazo para a maior importância do conflito demarcação vs integração (Kriesi et al., 2006), do qual o populismo tem vindo a tirar dividendos.

Já os países da Europa Ocidental, de um modo geral, sofreram de forma modesta com a crise, não tendo também sinais de crise política. Como tal, os efeitos da crise sobre o populismo foram moderados, existindo em todos os países desta região partidos populistas duradouros e fortemente incrustados nos sistemas 
partidários. A única exceção é a França, onde a Front National verificou um sucesso espantoso, que os autores explicam com o sentimento geral de mau funcionamento da política e da economia existente no país, que a crise ajudou a fortalecer, e que a liderança de Marine Le Pen soube explorar de forma hábil.

No que diz respeito à Europa do Sul, cujos países analisados sofreram severas crises, tanto a nível económico como político, os autores concluem, como previsto pelas suas hipóteses, que o populismo teve grandes ganhos eleitorais.

Por sua vez, a análise que fazem da Europa Central e de Leste, bastante afetada pela crise económica, leva-os a concluir que o populismo cresceu nos países dessa região incluídos na análise. A única exceção é a Polónia que, tendo tido uma boa performance económica, em termos comparativos, não verificou nenhum aumento do populismo - pelo menos à data de edição do livro. Em relação à crise política, todos estes países verificavam níveis muito baixos de confiança nas instituições e de satisfação com a democracia. Contra este pano de fundo, um conjunto de características específicas de cada país terá ditado o maior ou menor sucesso dos partidos populistas em cada um.

A última região corresponde aos países Anglo-Célticos, onde, ao contrário das restantes regiões, não existiam partidos populistas dignos de nota antes da crise. Estes países foram bastante afetados pela crise económica. Já os seus indicadores de crise política, ainda que tendo visto os seus valores decrescer, mantiveram-se acima da média europeia. Assim, de acordo com a expectativa dos autores, no Reino Unido o UKIP teve grande sucesso eleitoral. Por contraste, o outro país analisado, a República da Irlanda, contrariamente à expectativa dos autores, não viu emergir nenhum partido populista. A explicação dada para esse facto é a de que o sistema político irlandês exibe um conjunto de características que dificultam o sucesso de novos partidos. Em contrapartida, facilita bastante a eleição de deputados independentes, pelo que estes acabaram por mobilizar grande parte dos sentimentos antissistémicos. Por outro lado, se é certo que nenhum partido populista emergiu como consequência da crise, é também certo que este país verificou uma difusão do discurso populista pela totalidade do espetro partidário.

Posto isto, uma análise agregada do espaço europeu leva os autores a concluir que o populismo teve um crescimento notável na Europa durante a crise, tendência que consideram ter toda a probabilidade de vir a ser duradoura. Já no que diz respeito às hipóteses avançadas pelos autores, estes concluem que, apesar de se verificarem várias exceções, acabam por ter forte corroboração empírica. Há, no entanto, um conjunto de fatores políticos específicos de cada país, muitas vezes não relacionados com a crise, que desempenham um papel importante em muitos dos casos.

Esta robusta obra tem assim o contributo de se constituir como a primeira análise sistemática da influência da crise sobre o sucesso do populismo europeu. Se, por um lado, o pouco tempo passado desde o eclodir da crise dificulta que se analise até que ponto as tendências encontradas pelos autores se manterão no longo prazo, por outro lado o livro permite refutar algumas ideias erróneas bastante difundidas acerca do fenómeno do populismo. Por exemplo, o livro mostra como o populismo na Europa Ocidental, em vez de estar a aumentar, tem antes vindo a sofrer perdas eleitorais, ainda que modestas. Mostra também que, ao contrário da 
crença existente em grande parte opinião pública europeia, o populismo não tem sido uniformemente forte no Centro e Leste Europeu. Nesta região, os partidos populistas parecem antes ter tido períodos de sucesso intercalados com períodos de derrotas eleitorais.

Para além disso, o livro levanta também questões importantes que poderão vir a ser exploradas pela literatura futura. Uma dessas questões é a descoberta de que os partidos populistas, quando estão no poder como membro maioritário de uma coligação ou sem parceiros de coligação, tendem a intensificar o caráter populista do seu discurso, em vez de o moderar.

No entanto, não deixa de ser de assinalar a ausência de capítulos dedicados a Portugal e Espanha. Uma análise destes casos, para além de ser particularmente interessante para o leitor português ou espanhol, permitiria também um estudo mais completo do populismo na Europa do Sul. A análise do caso português seria particularmente interessante porque, sendo um país fortemente afetado pela crise económica e não tendo gerado nenhum caso de populismo, poderia levar a reconsiderar as conclusões dos autores em relação a esta região.

Outra crítica que se pode apontar à obra é em relação a uma certa mensagem normativa que lhe está implícita, a favor da manutenção do status quo europeu. Esta posição é particularmente clara quando os autores se referem ao caso grego como mostrando a importância de atores externos (neste caso, a Troika) em forçar os partidos populistas a terem uma atitude responsável. Os autores parecem ser de tal forma favoráveis aos partidos políticos consolidados que acabam por ignorar a pertinência de algumas das reivindicações dos partidos exteriores a esse grupo. Esta posição leva-os a parecerem por vezes demasiado abrangentes naquilo que consideram como partidos populistas - a inclusão do Syriza nesse grupo parece-me particularmente discutível -, o que os impede de considerar a pertinência de algumas das críticas que estes apontam ao sistema. Assim, há algo de paradoxal na posição dos autores: por um lado, lamentam a menor capacidade de representação dos partidos políticos mainstream, principalmente na Europa Ocidental. Por outro lado, consideram quaisquer partidos que ponham em causa o status quo como sendo populistas. Desta forma, não parecem admitir a possibilidade de uma posição intermédia: partidos que desafiem o sistema, apontando as falhas nele existentes que são responsáveis pela sua incapacidade de representar de forma eficaz os interesses das suas populações, mas sem serem populistas. ${ }^{1} \mathrm{E}$, não vendo esta terceira alternativa, os autores preferem a manutenção do status quo. No entanto, se o populismo tem vindo a ter sucesso, naquilo que parece ser uma consistente tendência de longo prazo, não será pelo facto de os partidos mainstream se fecharem em si, desvalorizando os motivos do aumento do apelo populista, que conseguirão travar tal sucesso.

Pelo contrário, esse fechamento não mais fará do que alimentar os sentimentos antissistémicos que tanto favorecem o populismo.

1 Esta distinção entre partidos populistas e partidos antissistémicos, ainda que sendo expressamente feita no capítulo dedicado à Eslováquia, nem sempre parece estar presente nos restantes capítulos da obra. 
No entanto, no cômputo geral da obra, esta questão acaba por ser menor e, como referido, passa essencialmente de forma implícita. Não deve, por isso, alhear-nos do facto de estarmos perante uma obra importante, cuja análise sistemática contribui não só para a nossa compreensão da influência que a recente crise económica e financeira teve no sucesso dos partidos populistas, mas também para o nosso entendimento do fenómeno do populismo, de um modo geral.

\section{Referências bibliográficas}

Kriesi, Hanspeter, Edgar Grande, Romain Lachat, Martin Dolezal, Simon Bornschier e Tim Frey (2006), "Globalization and the transformation of the national political space: six European countries compared", European Journal of Political Research, 45 (6), pp. 921-957.

Mudde, Cas (2004), "The populist zeitgeist", Government and Opposition, 39 (4), pp. 542-563.

Vicente Valentim. Mestrando em Ciência Política, pelo ISCTE-IUL. Instituto Universitário de Lisboa (ISCTE-IUL), Lisboa, Portugal.

E-mail: vicentedinisvalentim@gmail.com 
